\title{
From molecules to system failure: translational frontiers of multimodal imaging in neurodegenerative diseases
}

\author{
Thilo van Eimeren ${ }^{1,2,3}$ (D) A Alexander Drzezga ${ }^{1,2,4}$
}

Received: 22 September 2019 / Accepted: 27 September 2019 / Published online: 30 October 2019

(C) Springer-Verlag GmbH Germany, part of Springer Nature 2019

Understanding the molecular and neural underpinnings of neurodegenerative diseases is one of the greatest challenges in today's health-related research. To this end, the translation of evidence from basic science (e.g., at the molecular, cellular, or animal model level) to clinical science is paramount, yet remains particularly hard to achieve. Simultaneously, the plethora of evidence for the clinical utility of molecular imaging has not yet lead to a sufficiently available and standardized use in clinical practice and there is a critical need of a science-toguidelines transition of these techniques. Both tasks demand an iterative, multi-disciplinary, highly collaborative approach. Following this formula, we started a biannual symposiumcalled "Multimodal Imaging in Neurodegeneration Cologne," or short MINC - specifically dedicated to bridge translational gaps in particularly topical areas of research in neurodegenerative diseases. The MINC symposium in October 2018 was focused on five topics: the cause and effect of cerebral protein aggregation pathologies (beta-amyloid, tau, and alpha-synuclein), the various facets of neuroinflammation in neurodegenerative diseases, non-dopaminergic transmitter dysfunction in Parkinson's disease, and the development of proteinaceous agents for molecular PET imaging and for therapy. The great success of this meeting was largely due to the gathering and

This article is part of the Topical Collection on Neurology

Thilo van Eimeren

thilo.van-eimeren@uk-koeln.de

1 Multimodal Neuroimaging Group, Department of Nuclear Medicine, University of Cologne, Cologne, Germany

2 German Center for Neurodegenerative Diseases (DZNE), Bonn-Cologne, Germany

3 Department of Neurology, University of Cologne, Cologne, Germany

4 Molecular Organization of the Brain, Institute of Neuroscience and Medicine (INM-2), Research Center Jülich, Jülich, Germany interaction of scientist from various disciplines who would not usually meet at their respective science meetings. The 2 days of talks and discussions by experts in various fields from basic to clinical science and imaging yielded many intriguing insights. We have asked teams of participants of the meeting to summarize the main insights from this meeting. This resulted in three key chapters, which are outlined below and discussed in greater depth in three papers, which are published in this issue. We are extremely grateful to the Deutsche Forschungsgemeinschaft (DFG) for funding the MINC symposium (EI 892/5-1) and to the European Journal of Nuclear Medicine and Molecular Imaging for publishing these major outcomes of the MINC symposium as three separate publications in this issue.

\section{Connectomics and molecular imaging}

Neurodegenerative diseases such as Alzheimer's disease (AD), Parkinson's disease (PD), Pick's disease, and many more are characterized by pathological aggregation of misfolded proteins comprising beta-amyloid, tau, or alphasynuclein [1-3]. The distribution of these protein aggregates across brain areas over time has been described to typically follow protein-specific sequences or "stages" [4-6]. However, many cases show atypical temporo-spatial patterns of pathology distribution, such as the posterior cortical atrophy variant of AD pathology [7]. A better understanding of the governing principles underlying the temporo-spatial propagation of protein pathology would certainly be instrumental for the development and testing of therapies aiming at slowing or halting the propagation of pathological protein aggregates in these diseases. Bischof et al. summarize in this issue, how the combination of molecular information from PET and information about network connectivity (obtained with MRI or EEG) provided critical added utility for the understanding of the propagation of protein pathology across the human brain [8]. In sum, they report cumulative evidence for a triad of vulnerability, comprising the specific strain of misfolded protein (e.g., 
Pick-Tau vs. Alzheimer-Tau; see $[9,10])$, local cellular properties (e.g., MAPT gene expression; see [11]), and the way brain areas are functionally and structurally connected (“connectomics"; see [12]).

\section{Neuroinflammation beyond TSPO}

Inflammation plays a critical role as a disease-modifying factor in neurodegenerative diseases and may even be involved in its etiology [13]. Various microglial and astrocytic regulators of inflammatory processes have been identified in basic science. However, PET imaging of neuroinflammation has largely revolved around the increased expression of translocator protein $18 \mathrm{kDa}$ (TSPO) on the membranes of activated microglia which is associated with specific challenges such as highly variable ligand affinity. Considering these challenges and the prominent role of other inflammatory pathways, there is a dire need for neuroimaging tracers of neuroinflammatory processes beyond TSPO. In this issue, Boche et al. revisit these issues and describe advancements and challenges of novel methods with the potential to overcome the described challenges in imaging of neuroinflammation [14].

\section{Anti-body-based PET tracers}

A wealth of radioligands for in vivo detection and quantification of protein pathology with PET show enormous utility for diagnostic, prognostic, and scientific purposes in various neurodegenerative diseases (e.g., [15]). However, ligands for crucial areas of cellular and extracellular processes in neurodegeneration are not yet available for PET imaging. This includes, for example, ligands for soluble forms of tau or amyloid- $\beta$ aggregates, specific ligands for particular tau strains $[9,10]$, or ligands for any form of alpha-synuclein pathology in PD (see Alpha Synuclein Imaging Prize of the Michael J Fox Foundation [16]). Traditionally, PET radioligands for the central nervous system (CNS) have been limited to small molecule tracers, able to pass the blood-brain barrier. However, these small molecules may have particular disadvantages regarding specific binding to beta-sheet protein structures. Since antibody-based markers are state of the art for in vitro detection of protein aggregates, it is of great interest that Trojan horse-like strategies can be used to bring anti-body-based radioligands across the bloodbrain barrier [17]. Sehlin and Syvänen, on behalf of the MINC faculty, portrait the great potential opened up by sub-molecular characterization of protein pathology and the engineering of novel proteinaceous (e.g., antibody based) PET ligands to overcome critical challenges in imaging pathology in neurodegenerative diseases [18].
The abovementioned translational frontiers are far from resolved and demand continued long-term inter-disciplinary dedication. We will continue to explore these and new translational frontiers to be discussed in the upcoming MINC symposium scheduled for May 2020 (minc.uk-koeln.de).

Funding information This study was funded by Deutsche Forschungsgemeinschaft (DFG) (EI 892/5-1).

\section{Compliance with ethical standards}

Conflict of interest The authors declare that they have no conflict of interest.

Informed consent No animals were involved in writing this editorial. No humans were involved in writing this editorial, other than the authors.

Ethical approval This article does not contain any studies with human participants or animals performed by any of the authors.

\section{References}

1. Eisenberg D, Jucker M. The amyloid state of proteins in human diseases. Cell. 2012;148:1188-203.

2. Goedert M, Eisenberg DS, Crowther RA. Propagation of Tau Aggregates and Neurodegeneration. Annu Rev Neurosci. 2017;40:189-210.

3. Trojanowski JQ, Lee VM. Aggregation of neurofilament and alphasynuclein proteins in Lewy bodies: implications for the pathogenesis of Parkinson disease and Lewy body dementia. Arch Neurol. 1998;55:151-2.

4. Thal DR, Rüb U, Orantes M, Braak H. Phases of A beta-deposition in the human brain and its relevance for the development of $\mathrm{AD}$. Neurology. 2002;58:1791-800.

5. Braak H, Braak E. Frequency of stages of Alzheimer-related lesions in different age categories. Neurobiol Aging. 1997;18:351-7.

6. Braak H, Braak E. Staging of Alzheimer's disease-related neurofibrillary changes. Neurobiol Aging. 1995;16:271-8 discussion 278-84.

7. Dronse J, Fliessbach K, Bischof GN, von Reutern B, Faber J, Hammes $J$, et al. In vivo patterns of tau pathology, amyloid- $\beta$ burden, and neuronal dysfunction in clinical variants of Alzheimer's Disease. J Alzheimers Dis. 2017;55:465-71.

8. Bischof GN, Ewers M, Franzmeier N, Grothe MJ, Hoenig M, Kocagoncu E, Neitzel J, Rowe JB, Strafella A, Drzezga A, van Eimeren T; MINC faculty. Connectomics and molecular imaging in neurodegeneration. Eur J Nucl Med Mol Imaging. 2019 Jul 11.

9. Falcon B, Zhang W, Murzin AG, Murshudov G, Garringer HJ, Vidal R, et al. Structures of filaments from Pick's disease reveal a novel tau protein fold. Nature. 2018;561:137-40.

10. Fitzpatrick AWP, Falcon B, He S, Murzin AG, Murshudov G, Garringer HJ, et al. Cryo-EM structures of tau filaments from Alzheimer's disease. Nature. 2017;547:185-90.

11. Grothe MJ, Sepulcre J, Gonzalez-Escamilla G, Jelistratova I, Schöll M, Hansson O, et al. Molecular properties underlying regional vulnerability to Alzheimer's disease pathology. Brain. 2018;141:2755-71.

12. Bullmore E, Sporns O. Complex brain networks: graph theoretical analysis of structural and functional systems. Nat Rev Neurosci. 2009;10:186-98. 
13. Heneka MT, Carson MJ, El Khoury J, Landreth GE, Brosseron F, Feinstein DL, et al. Neuroinflammation in Alzheimer's disease. Lancet Neurol. 2015;14(4):388-405.

14. Boche D, Gerhard A, Rodriguez-Vieitez; MINC faculty. Prospects and challenges of imaging neuroinflammation beyond TSPO in Alzheimer's disease. Eur J Nucl Med Mol Imaging. 2019.

15. Hammes J, Drzezga A, van Eimeren T. The Role of Tau Imaging in Parkinsonian Disorders. Curr Neurol Neurosci Rep. 2018 Oct 6;18(12):86.
16. https://www.michaeljfox.org/news/alpha-synuclein-imaging-prize

17. Sehlin D, Fang XT, Cato L, Antoni G, Lannfelt L, Syvänen S. Antibody-based PET imaging of amyloid beta in mouse models of Alzheimer's disease. Nat Commun. 2016;7:10759.

18. Sehlin D, Syvänen S; MINC faculty. Engineered antibodies: new possibilities for brain PET? Eur J Nucl Med Mol Imaging. 2019

Publisher's note Springer Nature remains neutral with regard to jurisdictional claims in published maps and institutional affiliations. 